\title{
Introduction to Deconstructing Privilege in the Classroom: Teaching as a Racialized Pedagogy
}

\author{
Shilpi Sinha ${ }^{1}(\mathbb{D})$ Shaireen Rasheed ${ }^{2}$
}

Published online: 30 March 2018

(C) Springer Science+Business Media B.V., part of Springer Nature 2018

In a post-Trump climate in the United States, racial tensions and societal divisions have been on the rise. Educational institutions themselves have been the sites of these divisions and tensions, as evidenced by a rise in hate crimes across college campuses and incidences of bullying of immigrant youth in schools. Conversations on diversity and difference through the lens of multiculturalism and tolerance can no longer adequately address issues surrounding the Black Lives Matter movement, The Muslim Ban, current Homophobic policies against LGBTQIA and xenophobic policies targeted towards Hispanics and other immigrant groups.

The essays in this series deconstruct issues of privilege and race in the classroom by bringing to bear the lens of intersectionality to philosophical thought. Ethical teacher-student interactions described through relational and postmodern accounts emphasize teachers' openness, vulnerability and responsiveness to their students, signifying an embodied account of interaction. However, what has been missing from this discussion is how teachers' embodiment is also fundamentally racialized and what effect this may have on the very interactions being described, explored or valued. An underlying assumption of the essays in this special issue is that responsive and hospitable addressing of the societal tensions and divisions that emerge in higher education classrooms, especially those situated in teacher education programs within predominantly white institutions, can only begin to be evinced

Versions of the papers in this issue were presented as part of the 2017 Philosophy of Education Society annual conference panel entitled, "Putting the Ethics of Hospitality in Conversation with Raced Bodies and their Experiences," in Seattle, Washington.

Shilpi Sinha

Sinha@adelphi.edu

Shaireen Rasheed

srasheed@liu.edu

1 Philosophical Foundations of Education, Ruth S. Ammon School of Education, Adelphi University, 1 South Ave., Garden City, NY 11530, USA

2 Philosophical Foundations, Diversity and Social Justice, Post Campus of Long Island University, 720 Northern Blvd., Brookville, NY 11548, USA 
if the racialized embodiment of the educator, with all its epistemological and ontological associations is acknowledged and foregrounded. Thus, the purpose of this issue is twofold: first it is an invitation to re-think educational spaces in relation to the racialized bodies of educators and students, and second, to re-think what it might mean within the higher education classroom for hospitality to be enacted through the racialized bodies of educators, where the racialized body encompasses educators of color as well as white educators. Accordingly, some of the questions explored in this issue are the following: How might educators of color be better supported in institutions of higher education? How do educators create pedagogical spaces to help students understand privilege? What happens when students are resistant to understanding issues of privilege? What happens when we ask students to reflect on their intersectional identities and their multiple lived experiences? How do educators construct their own racialized identities in relation to their students when discussing issues of privilege in the classroom? How are we "ambushed" (Yancy 2012, 2017) by our own racialized bodies in relation to race and privilege?

While each of the essays contain different points of emphasis, a common thread may be evidenced in that teaching, understood through the orientation of the racialized bodies of educators, is linked in some form to teacher desire, be it the desire for right-relation (Bryzzheva), the never complete, not-an-end-itself desire of the teacher for the fundamentally unknowable student (Rasheed), or the desire for a connection with one's students that enables both student and teacher to interrogate their positionalities (Sinha). Teaching hospitably as understood through racialized bodies necessitates a grappling with teacher desire that is not a priori antithetical to the ethic of hospitality, but rather, may allow the teacher to live through the very tension between the singular and universal, or politics and ethics in a way that does not deny the significance of what it means to be a racialized body.

In "The Racialized Body of the Educator and the Ethic of Hospitality: The Potential for Social Justice Education Re-visited," Shilpi Sinha examines how the racialized bodies of educators of color inform their relation to the ethic of hospitality as they interact with their white students. Utilizing Claudia W. Ruitenberg's analysis of Jacques Derrida's conception of the aporias of hospitality, Sinha argues that it is only by paying attention to the phenomenological difference that characterizes raced bodies of color that one may understand how educators of color may best comport themselves to the tension between the self-preservation and self-annihilation that mark the aporias of hospitality. She shows that the racialized body of the educator of color often demands a distinctive comportment towards the tension, which is indicative not of a denial of the ethic of hospitality, but rather, a sojourning with one part of the non-dialectical tensions that characterize hospitality's aporias. Drawing on Charles W. Mills, Linda Alcoff and Sara Ahmed, Sinha lays out the socio-political materiality of race, which is constructed through its relation to (non-ontological) whiteness and white privilege, thereby pointing to the debasement, dispossession and disorientation that has marked and continues to mark bodies of color to this present day. Consequently, she draws attention to the pedagogical implications of the racialized bodies of educators of color in interaction with the white bodies of their students, offering a two-pronged perspective: (1) how faculty of color in institutions of higher education may be better supported given the cognitive, perceptual, affective, physical, spatial and economic effects of the socio-political materiality of race and (2) how the ethic of hospitality may be taken up by educators of color in ways that the alterity of their white students may be honored while also honoring the lived reality of racialized bodies that is not shed when one takes on the role of teacher.

In 'From Hostility to Hospitality: Teaching Anti-Racist Pedagogy in a Post-Election Climate,' Shaireen Rasheed discusses the challenges faced by educators of color when 
discussing issues of privilege and race with a predominantly white student body. By elaborating on Irigaray's notion of hospitality from the point of view of education, Rasheed offers an alternative phenomenological pedagogy of understanding the other, one that connects issues of positionality and orientation with those of an embodied epistemology of difference.

By using examples from her own classroom, Rasheed elucidates how she attempts to create phenomenological, transformative, intersectional anti-racist pedagogies grounded in critical self-reflection, where students are engaging in an authentic discourse on the nature of their positionality. This means taking a hard and self-reflective look at how racism, classism and sexism are often embodied in discussions of privilege. By problematizing notions of multiculturalism, tolerance and neutrality that often accompany discussions on race and white privilege, Rasheed urges educators and students to take up ethical questions that confront the concrete political realities of our times in the classroom. Furthermore, she uses such methodologies to facilitate reflection on the part of the students to study the ontic meanings of their own localized positionalities, and how they construct their different realities and objectivities, as entities, occurrences, processes, events, and facts.

In "This is a White Space: On Restorative Possibilities of Hospitality in a Raced Space," Lyudmila Bryzzheva explores the role of the restorative classroom as a methodological tool to create a 'right-relation' pedagogy of racial and social justice. Contextualized within Martin Buber's I-Thou relationship, she explains right-relation as a central value and an ideal outcome of restorative practices. The I-Thou relationship requires presence, openness and responsiveness. Dialogue that does not appropriate or objectify the Other is a part of all I-Thou relationships and it takes place both in spoken and non-verbal communication. Thus, Buber points to the between, the interhuman world of relation where meeting takes place.

But in spite of intentionally trying to create a race-conscious right relation restorative justice framework in her classroom, Bryzzheva explains how she ended up constructing a white space over and over again, until one black female student told her that she was not learning much in her class and a colleague of color having observed her and having read her syllabus, told her that the class benefited mostly white students. In her positionality as a white educator, Bryzzheva realized that often predominantly white classroom spaces marginalize students of color. In her sustained effort to problematize her own 'historico-racial habits' when engaging in predominantly white spaces, she envisions an alternative ethics of hospitality, one that allows her to create 'aporias of unknowability' to quote Claudia Ruitenberg. Using Ruitenberg's, Sara Ahmed's and Luce Irigaray's concept of hospitality, Bryzzheva further explores how notions of white privilege and race can be deconstructed in classrooms to include non-white spaces. By engaging in questions such as, "What made the space white? How might hospitality affect the restorative possibilities of and in the space?," she reconceptualizes right-relation as that which necessitates hospitality.

Responding to the above three essays, Claudia W. Ruitenberg, in "Hospitality and Embodied Encounters in Educational Spaces," highlights how Bryzzheva extends the work on hospitality and education by exploring how educational spaces can be marked by whiteness and how hospitality is denied if white educators do not interrogate and change the whiteness of such spaces as they teach racialized students. Ruitenberg further highlight's Bryzzheva's essay as illustrating the inevitable tension that arises when she attempts to create equitable spaces in her classroom: a tension between acknowledging one's students' experiences as raced individuals affected by structural injustice, and the alterity of the Other where the Other cannot be reduced to a substitutable example of any social category of difference. Bryzzheva's description of her classroom experiences thus serve 
to showcase, for Ruitenberg, how hospitality is rent by the impossible demand of seeing the student simultaneously through a singular and universal lens, which serves to further underscore, according to Ruitenberg, that while hospitality is challenged by categorizations of social difference and inequality, such as racialization, it is not determined by it.

In contrast to Bryzzheva, Ruitenberg notes that Rasheed and Sinha, in their respective essays, examine hospitality from the perspective of racialized educators in interaction with their white students. Ruitenberg emphasizes that an ethic of hospitality is amenable to educational discomfort visited upon students, where students are to be given a realistic understanding of the world they are coming into, as characterized through racial realities, the struggles of the marginalized and oppressed, and the history of how things have come to be the way they are. Ruitenberg points to Rasheed's delineations of her classroom interactions with her white students where she provides her students with an honest accounting of being a Muslim and not white, in a white world, to be illustrative of the educational discomfort appropriate to the ethic of hospitality. Ruitenberg underscores that while the combatting of ignorance may be uncomfortable for students, it does not prevent students from the possibility of finding a place in the world. Finally, Ruitenberg situates Sinha's essay within the broader question of whether the ethic of hospitality can offer anything to the educational situation where students overtly express oppressive ideas. It is here that some points of contention can be seen to arise between Sinha's uptake of the ethic of hospitality in relation to the racialized body of the educator, and Ruitenberg's interpretation of the ethic of hospitality, with reference to the very notions of how such an ethic is to be understood in relation to the ideas of reciprocity, the teacher's asymmetrical responsibility and desire.

Acknowledgements We would like to thank the reviewers for their very helpful and constructive feedback on the essays in this special issue.

\section{References}

Yancy, G. 2012. Look, a White! Philosophical essays on whiteness. Philadelphia, PA: Temple University Press.

Yancy, G. 2017. Black bodies, white gazes: The continuing significance of race in America, 2nd ed. Lanham, MD: Rowman \& Littlefield. 